\title{
Interação entre Extroversão e Conhecimento Astrológico em Estudantes Brasileiros ${ }^{1}$
}

\author{
Anna Mathilde Pacheco \\ Chaves Nagelschmidt \\ Universidade de São Paulo \\ Paulo Roberto Grangeiro Rodrigues ${ }^{2}$ \\ Universidade Paulista
}

\begin{abstract}
RESUMO - Usamos o Questionário dos 16 Fatores de Personalidade para investigar diferenças em Extroversão segundo a escala astrológica Frio-Quente (signos pares-signos ímpares) em 589 estudantes universitários brasileiros de ambos os sexos, de 19 anos e 6 meses a 51 anos e 1 mês, diferenciando entre conhecedores (208) e não conhecedores (381) da astrologia, sendo o conhecimento constituído na descrição de três características do signo solar. Foi dada a parte do grupo (266) a sugestão "Esta é uma pesquisa sobre astrologia", enquanto para a outra parte (323) foi dito que seria "uma pesquisa sobre personalidade". A ANOVA não revelou diferenças astrológicas $(p \geq 0,10)$ em nenhum dos grupos. Os conhecedores apresentaram maior Extroversão comparados aos não conhecedores $(p=0,01)$. Essa diferença foi devida aos resultados dos participantes dos signos Quentes $(p=0,0007)$, indicando a confirmação da maior suscetibilidade à informação vinda de fora sobre suas personalidades para estes.
\end{abstract}

Palavras-chave: personalidade; autoconceito; astrologia; Questionário de dezesseis fatores de personalidade; atribuição de causalidade.

\section{Interaction between Extroversion and Astrological Knowledge in Brazilian Students}

\begin{abstract}
We used 16PF Questionnaire to investigate differences in Extroversion according to the Cold-Hot astrological scale (even-odd signs) in 589 Brazilian university students of both genders, ages ranging from 19 years and 6 months to 51 years and 1 month, differentiating them among knowledgeable (208) and non knowledgeable (381) of astrology, by the description of three characteristics of the solar sign. For part of the group (266) it was given the suggestion "This is a research on astrology", while for the other part (323) it was said that it would be "a research about personality". The ANOVA did not reveal astrological differences $(p \geq 0.10)$ in none of the groups. The knowledgeable ones presented larger Extroversion compared to the non knowledgeable ones ( $p=0.01)$. This difference was due to the results of Hot signs participants $(p=0.0007)$, indicating the confirmation of larger susceptibility to the outside information about their personalities.
\end{abstract}

Key words: personality; self-concept; astrology; 16 PF questionnaire; attribution of causality.

A pesquisa sobre as relações entre características de personalidade previstas pelos signos astrológicos e as dimensões medidas em testes psicológicos tem mostrado, antes de tudo, que os resultados confirmadores ocorrem fortemente apenas no grupo de participantes que conhecem essas características (Pawlik \& Buse, 1979), evidenciando um processo de auto-atribuição (Fourie, 1984). Citamos aqui, inicialmente, uma pesquisa delineada para isolar esse processo. Nela foi usado o ABV - Amsterdamse Biografische Vragenlijst, que é derivado do EPI - Eysenck Personality Inventory, para medir a Extroversão. Cada grupo foi dividido entre aqueles a

1 Trabalho originado da Tese de Doutoramento de Paulo Roberto Grangeiro Rodrigues, sob a supervisão da Professora Dra. Anna Mathilde Pacheco e Chaves Nagelschmidt, no Departamento de Psicologia Social e do Trabalho do Instituto de Psicologia da Universidade de São Paulo, defendida em 03/09/2004.

2 Endereço: R. Dona Maria Augusta F. Gomes, nº 151, apto. 12, Jd. das Indústrias, São José dos Campos, São Paulo, Brasil 1240-740. E-mail: granger@click21.com.br quem foi dito que seus testes eram para uma "pesquisa sobre características de personalidade", e outros a quem foi dito que era uma "pesquisa sobre astrologia", como sugestão para induzir mais no segundo grupo as respostas segundo a crença ou não na astrologia. Também foi investigado posteriormente se as pessoas tinham crença e conhecimento em astrologia, sendo esse conhecimento constituído na descrição de três características de seu Signo Solar. Os participantes foram então divididos entre "conhecedores", caso soubessem seus signos e descrevessem três características de personalidade correspondentes; e "não conhecedores" de astrologia, caso não descrevessem características, mesmo sabendo quais eram seus signos (Rooij, 1994). Apareceu significativamente entre os "conhecedores" o padrão chamado "dente-de-serra" esperado em função da teoria astrológica.

\section{Conhecimento Astrológico e Autoconceito}

Segundo os autores, nos resultados acima comentados sugere-se que a auto-atribuição (por crença na descrição astrológica de seu signo) influencia o autoconceito. Assim 
sendo, a sugestão "astrologia" também teve mais efeito no grupo dos "conhecedores" do que no grupo dos "não-conhecedores". Então, "as pessoas atribuem a si mesmas aqueles traços que pertencem a seu signo solar."

Segundo Rooij (1994), as respostas dadas nos questionários puderam ser condicionadas pelo "processo de auto-observação seletiva", no qual o sujeito focaliza conscientemente apenas os momentos em que agiu conforme o autoconceito astrológico, confirmando o que foi auto-atribuído.

Em continuidade a essa linha de pesquisa, Hamilton (1995) pesquisou a incorporação da informação astrológica no autoconceito. Pediu aos participantes que escolhessem, entre "pacotes" de traços astrológicos advindos dos signos (sem que fosse dito a origem desses traços), qual a melhor descrição de seu caráter. Nos resultados, os participantes que conheciam astrologia escolheram a descrição do próprio signo solar, de maneira significativamente diferente daquela dos participantes declarados não conhecedores da astrologia. A autora concluiu que "a exposição a descrições de personalidade baseadas astrologicamente pode afetar o autoconceito duradouro" (p. 715).

Refinando a pesquisa sobre o processo de auto-atribuição de características astrológicas, Rooij (1999) replicou essa pesquisa, desta vez correlacionou traços astrológicos separados, retirados também de manuais astrológicos, com o autoconceito de 422 pessoas, sendo selecionados oito traços para cada signo, quatro com conotações positivas e quatro com conotações negativas. Os participantes foram instruídos a classificar os 96 traços numa escala de cinco pontos indo desde " 1 = (não se aplica a mim)" até "5 = (aplica-se completamente a mim)". Os resultados demonstraram que para os participantes que conheciam astrologia (134), a escolha dos traços selecionados dos manuais era muito mais frequiente para traços do próprio signo (confirmado posteriormente pelo pedido da data de nascimento) do que a escolha de traços de outros signos, mesmo sem ter sido dito para as pessoas qual a origem da listagem dos traços. O mesmo já não ocorreu para os participantes que não conheciam astrologia. A medida do conhecimento astrológico foi a descrição de três características do signo solar tradicionalmente publicadas. Rooij concluiu que a pesquisa também sugeriu que a exposição à informação astrológica afeta de modo duradouro o autoconceito para aqueles participantes que têm conhecimento astrológico (Rooij, 1999).

No entanto, na pesquisa inicial de Rooij também foi encontrado que: a) há mais extrovertidos entre os conhecedores da astrologia. Assim, ser mais extrovertido provavelmente se relacionaria a crer mais em astrologia; b) a diferença (discrepância) nos resultados de extroversão entre o grupo dos que conhecem e o dos que não conhecem astrologia é maior entre os subgrupos ímpares (teoricamente extrovertidos segundo os signos por pertencerem aos Elementos Fogo e Ar = Quentes), do que entre os subgrupos pares (teoricamente introvertidos segundo os signos por pertencerem aos Elementos Terra e Água = Frios), “(...) o que não invalida totalmente a teoria astrológica"(Rooij, 1994, p. 987), ao menos no tocante a algum tipo de diferença entre esses dois grupos (signos ímpares e signos pares). Se a auto-atribuição de características astrológicas tivesse efeito uniforme, determinaria entre os conhecedores um aumento das médias dos ímpares e uma diminuição - na mesma proporção - das médias dos pares, também por auto-atribuição, portanto, a média no grupo de conhecedores continuaria muito próxima da média geral que, por sua vez, seria necessariamente acompanhada de perto pelas médias dos não conhecedores. $\mathrm{O}$ autor conclui que as pessoas nascidas naqueles períodos dos signos ímpares não são necessariamente mais extrovertidas, porém “(...) mais suscetíveis à informação vinda de fora sobre suas personalidades" (Rooij, 1994, p. 987).

Mas a "suscetibilidade" não seria um resultado devido ao fato de serem descrições mais favoráveis? Uma pesquisa de Hamilton (2001) descobriu que os participantes da amostra julgaram as descrições dos signos ímpares como mais favoráveis do que as dos signos pares. Contrariando os resultados dessa pesquisa, Wunder (2003) encontrou em 1700 participantes, na Alemanha, níveis de crença indiferentemente distribuídos entre os signos, comparando os de descrição mais favorável com os de descrição mais desfavorável. Pode ocorrer que a maior favorabilidade apenas induza a uma maior concordância das pessoas com as descrições de seus signos, mas que a menor favorabilidade das descrições não impeça a crença na astrologia para as pessoas de signos teoricamente introvertidos.

Levando em conta essas questões, delineamos então uma "replicação por constructo" (Lykken, 1968) da pesquisa de Rooij (1994), do mesmo modo controlando o "conhecimento da astrologia" dos participantes testados, mas com participantes brasileiros e utilizando o 16PF, de modo a investigar se a autoatribuição causa diferenças de resultados entre "conhecedores" e "não conhecedores" da astrologia, e também se há variações de base astrológica independentes da crença. O levantamento das publicações revelou que não havia pesquisas semelhantes anteriores feitas com brasileiros.

Geramos três hipóteses:

$1^{a}$ Hipótese: Entre os "conhecedores”, as médias grupais da Extroversão são significativamente mais altas para os signos Quentes do que para os signos Frios, mas o mesmo não ocorre entre as médias grupais dos "não conhecedores" (Hipótese da auto-atribuição = HA-A).

$2^{a}$ Hipótese: Há uma discrepância significativa das médias da Extroversão nos Quentes e "conhecedores" em relação às médias dos Quentes e "não conhecedores", e o mesmo não ocorre com as médias dos Frios e "conhecedores" em comparação com as médias dos Frios e "não conhecedores" (Hipótese da suscetibilidade à informação diferenciada pela dimensão Frio-Quente = HSFQ).

$3^{a}$ Hipótese: Os "conhecedores" se diferenciam dos "não conhecedores" significativamente para mais na Extroversão (Hipótese do conhecimento astrológico diferenciado por Extroversão $=\mathrm{HCE}$ ).

\section{Método}

\section{Participantes}

Foram reunidos no estudo os resultados de 750 participantes, alunos entre os primeiro e quarto anos de duas universidades em São José dos Campos, dos cursos: Admi- 
nistração de Empresas, Propaganda e Marketing, Publicidade e Propaganda, Turismo, Jornalismo. De 750 testes aplicados, foram selecionados 589, dado que eliminamos os testes de participantes com idades inferiores a 19 anos e 6 meses, em função das variações conhecidas dos traços até por volta dessa idade, conforme demonstrado por Cattell (1973). Também houve casos de questionários incompletos e de pessoas que não responderam as questões de conhecimento sobre astrologia. A composição da amostra está na Tabela 1.

Para dividir as pessoas entre os signos, adotamos o início dos signos Cardeais conforme a proposta astronômica dos inícios médios das estações: 20 de Março para Carneiro, 21 de Junho para Caranguejo, 23 de Setembro para Balança e 22 de Dezembro para Capricórnio (Murgel \& Perissinotto, 1988). Adotamos como início dos signos Fixos e Mutáveis - que seguem os Cardeais - as datas médias, conforme a divisão proposta de 30 em 30 graus de longitude zodiacal a partir dos Equinócios e Solstícios: 20 de Abril para Touro, 21

Tabela 1. Composição da amostra.

\begin{tabular}{cccc}
\hline & Homem & Mulher & $\boldsymbol{\Sigma}$ \\
Conhecedores & 112 & 96 & $208_{(35,31 \%)}$ \\
Não conhecedores & $156^{2}$ & 225 & $381_{(64,69 \%)}$ \\
$\boldsymbol{\Sigma}$ & $268_{(45,50 \%)}$ & $321_{(54,50 \%)}$ & 589 \\
\hline
\end{tabular}

Tabela 2. Distribuição da amostra por signo, por sugestão e conhecimento.

\begin{tabular}{|c|c|c|c|c|}
\hline \multicolumn{2}{|c|}{ Sugestão: Psicologia } & Conhecedores & $\begin{array}{c}\text { Não } \\
\text { Conhecedores }\end{array}$ & $\Sigma \Sigma$ \\
\hline \multirow{13}{*}{$\begin{array}{l}\text { Signo / } \\
\text { (início) }\end{array}$} & Carneiro $(20 / 03)$ & 9 & 16 & 25 \\
\hline & Touro $(20 / 04)$ & 6 & 18 & 24 \\
\hline & Gêmeos (21/05) & 11 & 15 & 26 \\
\hline & Caranguejo (21/06) & 12 & 16 & 28 \\
\hline & Leão $(22 / 07)$ & 9 & 11 & 20 \\
\hline & Virgem $(23 / 08)$ & 11 & 27 & 38 \\
\hline & Balança (23/09) & 5 & 17 & 22 \\
\hline & Escorpião (23/10) & 7 & 27 & 34 \\
\hline & Sagitário (22/11) & 8 & 14 & 22 \\
\hline & Capricórnio (22/12) & 6 & 22 & 28 \\
\hline & Aquário (20/01) & 9 & 23 & 32 \\
\hline & Peixes $(19 / 02)$ & 8 & 16 & 24 \\
\hline & $\Sigma$ & 101 & 222 & 323 \\
\hline \multicolumn{2}{|c|}{ Sugestão: astrologia } & Conhecedores & $\begin{array}{c}\text { Não } \\
\text { conhecedores }\end{array}$ & $\Sigma \Sigma$ \\
\hline \multirow{14}{*}{$\begin{array}{l}\text { Signo / } \\
\text { (início) }\end{array}$} & Carneiro $(20 / 03)$ & 9 & 13 & 22 \\
\hline & Touro (20/04) & 9 & 9 & 18 \\
\hline & Gêmeos (21/05) & 6 & 15 & 21 \\
\hline & Caranguejo (21/06) & 10 & 19 & 29 \\
\hline & Leão (22/07) & 9 & 15 & 24 \\
\hline & Virgem (23/08) & 11 & 14 & 25 \\
\hline & Balança (23/09) & 6 & 9 & 15 \\
\hline & Escorpião (23/10) & 12 & 10 & 22 \\
\hline & Sagitário (22/11) & 7 & 15 & 22 \\
\hline & Capricórnio (22/12) & 10 & 13 & 23 \\
\hline & Aquário (20/01) & 7 & 16 & 23 \\
\hline & Peixes $(19 / 02)$ & 11 & 11 & 22 \\
\hline & $\Sigma$ & 107 & 159 & 266 \\
\hline & $\Sigma \Sigma$ & 208 & 381 & 589 \\
\hline
\end{tabular}

de Maio para Gêmeos; 22 de Julho para Leão, 23 de Agosto para Virgem; 23 de outubro para Escorpião, 22 de Novembro para Sagitário; 20 de Janeiro para Aquário, 19 de Fevereiro para Peixes (Murgel \& Perissinotto, 1988).

No entanto, para as pessoas que nasceram nos dias de limite entre signos levamos em consideração o signo que declararam para garantir a possibilidade do efeito da auto-atribuição. Verificamos essas datas conforme definidas por um manual astrológico (Parker \& Parker, 1982), definindo o limite de um dia de diferença como aceitável, dado que o dia de mudança de signo não é astronomicamente fixo por diferenças entre o ano astronômico e o calendário. Em caso de discrepância maior, eliminamos os dados do sujeito da amostra. A distribuição da amostra é a detalhada na Tabela 2.

A faixa de idade da amostra foi de 19 anos e 6 meses a 51 anos e 1 mês. A média de idade foi 26 anos e 5 meses.

\section{Instrumentos}

Realizamos as aplicações dos testes utilizando o 16PF - Questionário dos 16 Fatores de Personalidade, traduzido por Eugênia Moraes de Andrade e Dulce de Godoy Alves, publicado pela CEPA, Rio de Janeiro. Extroversão é medida ali como "fator de segunda ordem", definida como a tendência da pessoa a ser “(...) socialmente expansiva, sem inibições, hábil em tratar e manter contatos interpessoais, (...)”. (Andrade \& Alves, 1993, p. 33). Para obtenção das medidas de Extroversão utilizamos as equações de estimação estabelecidas por Krug e Johns, em 1986, com 17.381 participantes nos EUA. A equação da Extroversão é: Extroversão = [0,28.A (Expansividade) $]+$ $[0,35 . F$ (Despreocupação) $]+[0,36 \cdot \mathrm{H}$ (Desenvoltura) $]-[0,38$. $\mathrm{Q}_{2}$ (Auto-Suficiência)] + 2,15 (Krug \& Johns, 1986).

Há uma correlação alta entre a Extroversão medida no EPI e a Extroversão medida no $16 \mathrm{PF}$, segundo mediu-se pelas cargas fatoriais das escalas: "A" $=(0,41), " F "=(0,65)$, "H" $=(0,77)$ e " $\mathrm{Q}_{2} "=(-0,43)$. E medida diretamente no EPI: como o fator $\mathrm{E}=(0,71)$, na pesquisa de correlação de Noller, Law e Comrey (1987).

Para controlar a variável "conhecimento da astrologia" foi criado um questionário para obter as mesmas informações citadas por Rooij, sendo aplicado após (para o grupo da sugestão: "Psicologia") ou antes de (para o grupo da sugestão: "Astrologia") os participantes terem entregado o questionário respondido. Constou das seguintes questões:

a) Você acredita em Astrologia?, b) Você acredita em influências astrológicas na personalidade?, c) Você acredita que as pessoas correspondem às descrições de seus signos astrológicos?, d) Você sabe qual é seu signo? Se sim, qual é?, e) Você pode descrever três características de seu signo? Se sim, quais são?, f) Você pode descrever o que é Ascendente?, g) Você sabe descrever o que é Meio-do-Céu? e h) Você sabe descrever o que são Casas astrológicas?

As três últimas questões são feitas para avaliar o grau de conhecimento astrológico da pessoa, pois são informações que só quem estuda mais profundamente astrologia pode ter.

\section{Procedimentos}

Responder o questionário é parte opcional da matéria Psicologia nos cursos citados, ao abordarmos o tema perso- 
nalidade. Os alunos responderam os questionários paralelamente a outro teste que foi aplicado, e o intuito era dar os resultados dos dois testes e compará-los. Os questionários foram coletados entre 1999 e 2003 . Há um estímulo à participação devido ao fato de terem interesse em saber sobre suas personalidades. Isso facilita uma parte do estudo, que é a composição de parte da amostra com participantes que recebem a sugestão "Psicologia", pois após a entrega dos testes foi pedido para eles que respondessem a uma "pesquisa sobre personalidade" com as questões adicionais sobre data de nascimento e conhecimento da astrologia. Também foi pedido para todos, o Termo de Consentimento Livre e Esclarecido.

Classificamos os participantes que responderam acreditar na astrologia e nas influências astrológicas, que sabiam seus signos e descreveram três características, que correspondessem às citadas no Anexo 1: Descrições dos Signos por "Traços" como conhecedores e aqueles que responderam não acreditar na astrologia nem em influências astrológicas e não descreveram três características como não conhecedores. Nos casos em que os participantes responderam acreditar na astrologia, mas não em influências astrológicas na personalidade e não descreveram características, houve uma classificação como não conhecedores. Participantes que responderam não acreditar na astrologia nem em influências astrológicas, mas que descreveram três características, foram classificados como conhecedores. Em muitos casos os participantes disseram não acreditar nem na astrologia nem nas influências astrológicas na personalidade, mas sabiam seus signos, sem descrever três características, foram classificados como não conhecedores.

A pergunta "Você acredita que as pessoas correspondem às descrições de seus signos astrológicos?" foi colocada como um controle para definir melhor o conhecimento das características em casos de discrepância entre crença e conhecimento, dado que para saber sobre a correspondência é necessário saber as características.

Foi então feita a ANOVA em três níveis, relacionando a escala com: Signo [Ímpar (ou Quente) vs. Par (ou Frio)] $\mathrm{X}$ Conhecimento astrológico (Descrição ou não de três características) X Sugestão (Psicologia vs. Astrologia). Tratamos todos os resultados em valores brutos.

\section{Resultados}

Extroversão na amostra dividida entre não conhecedores e conhecedores da astrologia

No grupo dos não conhecedores não há significância na variação, o que indicam as Tabelas 3 e 4. A Extroversão, ao menos como é medida no $16 \mathrm{PF}$, parece não depender de nenhuma maneira de um fator astrológico entre os não conhecedores das características de seus signos.

Entre os conhecedores há uma significação marginal para a diferenciação entre ímpares e pares, como expressam as Tabelas 5 e 6.

O grupo de conhecedores da astrologia apresentou média de Extroversão significativamente mais alta $(F=6,11$, $p=0,01)$ do que o grupo de não conhecedores, respectivamente 11,19 e 10,49 .

A Figura 1 mostra essas diferenças.

\section{Discussão}

Não foi confirmada a HA-A: Os signos Quentes entre os conhecedores não apresentaram resultados significativamente maiores em Extroversão em relação aos Frios. Isso pode

Tabela 3. Extroversão para grupo de não conhecedores.

\begin{tabular}{lcccc}
\hline Resumo & & & & \\
\hline Grupo & Contagem & Soma & Média & Variância \\
Signos ímpares & 179 & 1825,2 & 10,20 & 10,86 \\
Signos pares & 202 & 2170 & 10,74257 & 11,11029 \\
\hline
\end{tabular}

Tabela 4. ANOVA.

\begin{tabular}{lcccccc}
\hline $\begin{array}{l}\text { Fonte da } \\
\text { variação }\end{array}$ & $S Q$ & $g l$ & $M Q$ & $F$ & $\begin{array}{c}\text { Valor } \\
P\end{array}$ & $\begin{array}{c}F \\
\text { crítico }\end{array}$ \\
\hline $\begin{array}{l}\text { Entre } \\
\text { grupos }\end{array}$ & 28,28442275 & 1 & 28,28442 & 2,57288 & 0,1095 & 3,86619 \\
$\begin{array}{l}\text { Dentro } \\
\text { dos } \\
\text { grupos }\end{array}$ & 4166,45985 & 379 & 10,99330 & & & \\
$\Sigma$ & 4194,744273 & 380 & & & & \\
\hline
\end{tabular}

Tabela 5. Extroversão para grupo de conhecedores.

\begin{tabular}{lcccc}
\hline Resumo & & & & \\
\hline $\begin{array}{l}\text { Grupo } \\
\text { Contagem }\end{array}$ & Soma & Média & Variância \\
$\begin{array}{l}\text { Signos } \\
\text { impares }\end{array}$ & 96 & 1109,54 & 11,56 & 7,71 \\
$\begin{array}{l}\text { Signos } \\
\text { pares }\end{array}$ & 112 & 1218,76 & 10,88 & 9,29514 \\
\hline
\end{tabular}

Tabela 6. ANOVA

\begin{tabular}{lcccccc}
\hline $\begin{array}{l}\text { Fonte da } \\
\text { variação }\end{array}$ & $S Q$ & $g l$ & $M Q$ & $F$ & $\begin{array}{c}\text { Valor } \\
P\end{array}$ & $\begin{array}{c}F \\
\text { crítico }\end{array}$ \\
\hline $\begin{array}{l}\text { Entre } \\
\text { grupos }\end{array}$ & 23,61671 & 1 & 23,61674 & 2,75777 & 0,0984 & 3,88700 \\
$\begin{array}{l}\text { Dentro } \\
\text { dos } \\
\text { grupos }\end{array}$ & 1764,1269 & 206 & 8,5637230 & & & \\
$\mathbf{\Sigma}$ & & & & & & \\
\hline
\end{tabular}

ser devido ao fato de que, em nosso caso, uma minoria dos participantes $(266 / 589=45 \%)$ recebeu a sugestão Astrologia, não permitindo, talvez, um efeito da sugestão entre os ímpares \& conhecedores suficiente para diferenciá-los dos pares \& conhecedores. Na pesquisa de Rooij (1994), uma maioria $(331 / 500=66 \%)$ recebeu a sugestão.

Foi confirmada a HSFQ: Há discrepância significativa das médias da Extroversão nos Quentes \& conhecedores em relação às médias dos Quentes \& não conhecedores $(t=3,44312$, 


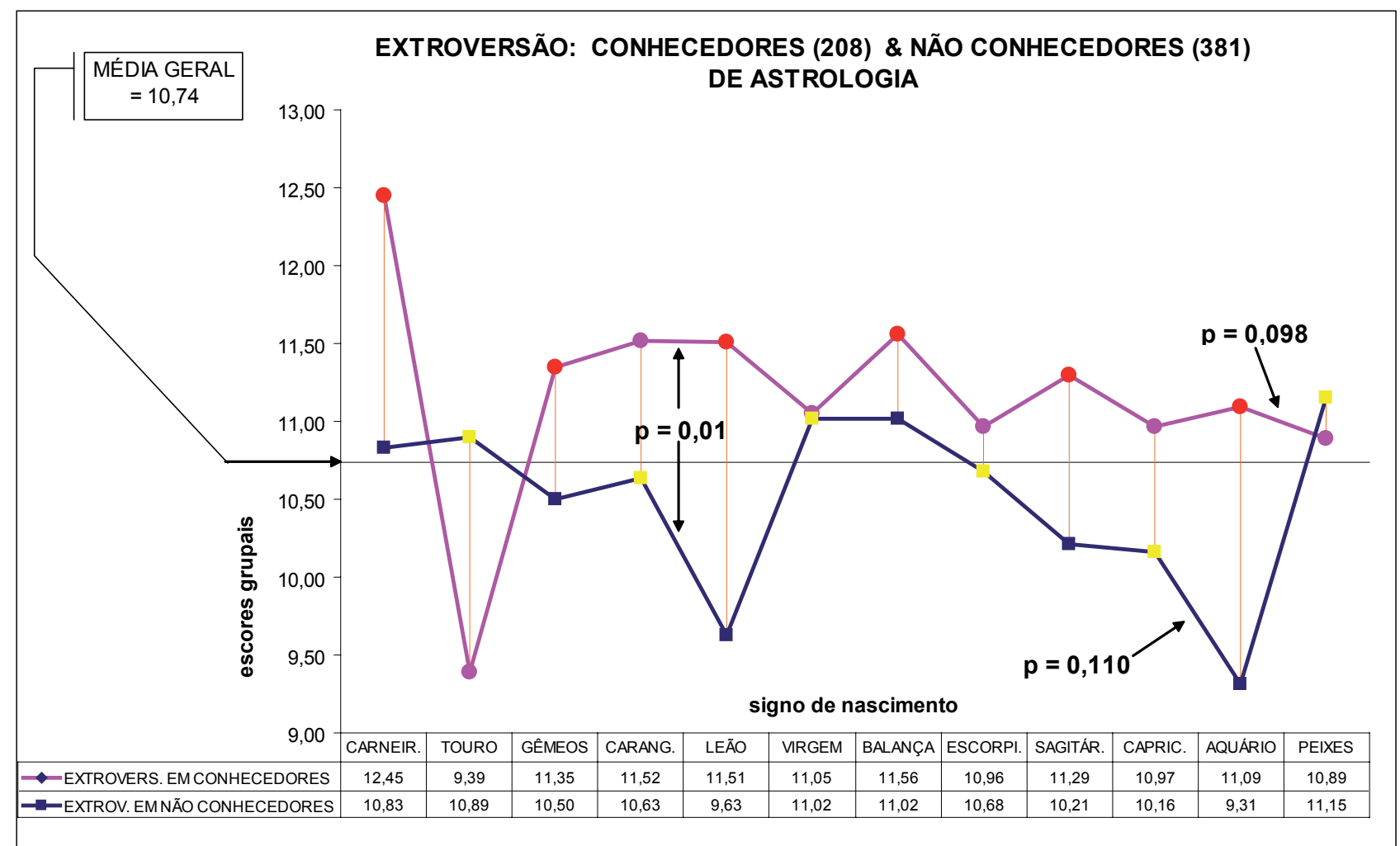

Figura 1. Distribuição da extroversão por signos e por conhecimento astrológico.

$p=0,0007)$ e o mesmo não ocorre com as médias dos Frios \& conhecedores em comparação com as médias dos Frios $\&$ não conhecedores $(t=0,36529, p=0,7200)$. A Extroversão variou diferencialmente entre Frios e Quentes.

Foi confirmada a HCE: Os conhecedores têm média significativamente mais alta em Extroversão do que os não conhecedores. Ainda que a significância do resultado não seja tão alta quanto a encontrada por Rooij (1994) $(p<0,005)$, a diferença se dá no mesmo sentido.

Dado que há quase uma uniformidade de resultados acima da média geral entre os conhecedores, podemos confirmar que a diferença entre as médias não seria apenas resultado do conhecimento da astrologia e crença em suas descrições nas respostas do questionário, mas antes a maior extroversão levou à maior probabilidade de conhecimento da astrologia. Talvez a astrologia - como forma de explicação das diferentes "personalidades" observadas nos outros e em si - faça mais sentido para as pessoas mais extrovertidas da amostra.

Muito provavelmente também os maiores resultados em Extroversão para os conhecedores não se devem a uma maior concordância com a característica desejável da Extroversão para os de signos ímpares, já que cinco dos signos pares se colocam acima da média geral.

Entendemos então que, também aqui aparece um fator de suscetibilidade ao mundo externo definido pela dimensão Frio-Quente, que intervém diferencialmente no efeito da auto-atribuição nos resultados da Extroversão para os conhecedores, que se observa também quando comparados com o total da amostra $(p=0,018)$. Confirmando um resultado não totalmente explorado por Rooij (1994), há na amostra uma diferença de base astrológica entre as pessoas de signos Quentes e Frios, que tornaria as primeiras mais suscetíveis ao externo em geral, e não só à informação sobre elas mesmas advindas do que leram ou ouviram.

Parece haver também um efeito de interação entre o fator de suscetibilidade e o autoconceito para os Quentes \& conhecedores por causa da coincidência da extroversão que observam em si mesmos com as descrições astrológicas que indicam extroversão. Desse modo, os resultados apontam que o autoconceito duradouro não se constrói apenas por informações obtidas por descrições externas, mas também pela auto-observação confirmadora - mas não seletiva do próprio comportamento que forneça subsídios para a auto-atribuição. Esta, ao ser freqüentemente confirmada se realizando nos comportamentos, torna-se uma crença estável sobre si mesmo.

\section{Referências}

Andrade, E. M. \& Alves, D. G. (1993). Questionário de 16 Fatores de Personalidade. Manual Abreviado (01.05). Rio de Janeiro: CEPA.

Cattell, R. B. (1973). Personality and mood by questionnaire. San Francisco: Jossey-Bass Publishers.

Noller, P., Law, H. \& Comrey, A. L. (1987). Cattell, Comrey and Eysenck personality factors compared: more evidence for the five robust factors? Journal of Personality and Social Psychology, 53(4), 775-782. 


\section{A. M. Pacheco e cols}

Fourie, D. (1984). Self- attribution theory and the sun-sign. Journal of Social Psychology, 122, 121-126.

Hamilton, M. M. (1995). Incorporation of astrology-based personality information into long-term self-concept. Journal of Social Behavior and Personality, 10, 707-718.

Hamilton, M. M. (2001). Who believes in astrology? Effect of astrologically derived personality descriptions on acceptance of astrology. Personality \& Individual Differences. 31(6), 895-902.

Krug, S. E. \& Johns, E. F. (1986). A large scale cross-validation of second order personality structure defined by the $16 \mathrm{PF}$ Psychological Reports, 59, 683-693.

Lykken, D. T. (1968). Statistical significance in psychological research. Psychological Bulletin, 70, 151-159.

Murgel, C. B. \& Perissinotto, N. (1988). Planisfério Celeste Rotativo (HS. 23.27). São Paulo: FUNBEC.

Parker, D. \& Parker, J. (1982). O Grande Livro da Astrologia. São Paulo: Círculo do Livro.

Pawlik, K. \& Buse, L. (1979). Selbst Attribuierung als differentiellpsychologische Moderator-variabele: Nachprüfung und Erklärung von Eysencks Astrologie Persönlich-keitsKorrelationen. [Self-attribution as a differential psychological moderator variable: check and explanations of Eysenck's Astrology-Personality-Correlations]. Zeitschrift für Sozialpsychologie, 10, 54-69.
Rooij, J. J. F. V. (1994). Introversion-Extraversion: astrology versus psychology. Personality and Individual Differences, 16(6), 985-988.

Rooij, J. J. F. V. (1999). Self-concept in terms of astrological sunsign traits. Psychological Reports, 84, 541-546.

Wunder, E. (2003). Self-attribution, sun-sign traits, and the alleged role of favourableness as a moderator variable: long-term effect or artefact? Personality and Individual Differences, 35(8), 1783-1789.

Recebido em 23.09.2005

Primeira decisão editorial em 16.12.2005

Versão final em 25.05.2006

Aceito em 07.06.2007 
Anexo 1. Descrições dos signos por "traços".

\begin{tabular}{|c|c|c|}
\hline Signo & Traços Positivos & Traços Negativos \\
\hline Áries (carneiro) & $\begin{array}{l}\text { Pioneiro, aventuroso, empreendedor, corajoso, direto, } \\
\text { enérgico, odeia restrição, ama liberdade }\end{array}$ & $\begin{array}{l}\text { Egoísta, egocêntrico, sem sutileza, impulsivo, belicoso, } \\
\text { satírico, irascível, impaciente }\end{array}$ \\
\hline Touro & $\begin{array}{l}\text { Prático, digno de confiança, paciente, hábil em negó- } \\
\text { cios, resistente, senso de valores, esteta, persistente, } \\
\text { determinado, afetivo, fidedigno }\end{array}$ & $\begin{array}{l}\text { Possessivo, preguiçoso, auto-indulgente, chato, obstinado, } \\
\text { inflexível, convencional, ganancioso, rancoroso, rotineiro }\end{array}$ \\
\hline Gêmeos & $\begin{array}{l}\text { Adaptável, versátil, intelectual, engenhoso, lógico, dili- } \\
\text { gente, espontâneo, jovial, comunicador }\end{array}$ & $\begin{array}{l}\text { Mutável, agitado, astucioso, inquisitivo, inconsistente, } \\
\text { duas caras, nervoso, superficial, fofoqueiro }\end{array}$ \\
\hline $\begin{array}{l}\text { Câncer } \\
\text { (caranguejo) }\end{array}$ & $\begin{array}{l}\text { Gentil, sensível, simpático, imaginativo, maternal ou } \\
\text { paternal, solícito, protetor, cauteloso, patriótico, tenaz, } \\
\text { perspicaz, frugal }\end{array}$ & $\begin{array}{l}\text { Superemotivo, hiper-sensível, mordaz, melindroso, mal- } \\
\text { humorado, mutável, rancoroso, instável, facilmente lison- } \\
\text { jeável, desmazelado }\end{array}$ \\
\hline Leão & $\begin{array}{l}\text { Magnânimo, generoso, criativo, entusiasmado, organi- } \\
\text { zador, indulgente, expansivo, dramático }\end{array}$ & $\begin{array}{l}\text { Dogmático, brigão, pomposo, esnobe, intolerante, fixo em } \\
\text { opiniões, condescendente, louco por poder, dissimulado }\end{array}$ \\
\hline Virgem & $\begin{array}{l}\text { Discriminativo, analítico, meticuloso, modesto, ordei- } \\
\text { ro, }\end{array}$ & $\begin{array}{l}\text { Minucioso, preocupado, hiper-crítico, afetado, convencio- } \\
\text { nal, enfadonho }\end{array}$ \\
\hline Libra (balança) & $\begin{array}{l}\text { Encantador, harmonioso, despreocupado, romântico, } \\
\text { diplomata, idealista, refinado }\end{array}$ & $\begin{array}{l}\text { Indeciso, rancoroso, frívolo, mutável, dado ao flerte, in- } \\
\text { fluenciável, crédulo, oscilante entre extremos }\end{array}$ \\
\hline Escorpião & $\begin{array}{l}\text { Intenso emocional e sentimentalmente, sentido de fina- } \\
\text { lidade, imaginativo, sutil, persistente, determinado }\end{array}$ & $\begin{array}{l}\text { Ciumento, rancoroso, teimoso, obstinado, intratável, reti- } \\
\text { cente, desconfiado }\end{array}$ \\
\hline Sagitário & $\begin{array}{l}\text { Jovial, otimista, versátil, mente aberta, adaptável, filo- } \\
\text { sófico, amante da liberdade, sincero, franco, fidedigno, } \\
\text { escrupuloso }\end{array}$ & $\begin{array}{l}\text { Exagerado, extremista, sem tato, inquieto, negligente, ce- } \\
\text { gamente otimista, turbulento, irresponsável, caprichoso }\end{array}$ \\
\hline Capricórnio & $\begin{array}{l}\text { Confiável, determinado, ambicioso, cuidadoso, pruden- } \\
\text { te, com senso de humor, disciplinado, paciente, perse- } \\
\text { verante }\end{array}$ & $\begin{array}{l}\text { Aparência rígida, superexigente, pessimista, convencio- } \\
\text { nal, mesquinho, avarento, desmancha-prazeres }\end{array}$ \\
\hline Aquário & $\begin{array}{l}\text { Humanitário, independente, cordial, prestativo, pro- } \\
\text { gressista, original, inventivo, reformista, fiel, leal, idea- } \\
\text { lista, inclinações intelectuais }\end{array}$ & $\begin{array}{l}\text { Imprevisível, excêntrico, rebelde, obstinado, sem tato, fixo } \\
\text { nas suas opiniões, caprichoso, anticonvencional }\end{array}$ \\
\hline Peixes & $\begin{array}{l}\text { Humilde, compassivo, simpático, emotivo, desprendi- } \\
\text { do, sensível, adaptável, impressionável, gentil, intuiti- } \\
\text { vo, receptivo }\end{array}$ & $\begin{array}{l}\text { Dúbio, negligente, reticente, confuso, pouco prático, fraca } \\
\text { vontade, indeciso }\end{array}$ \\
\hline
\end{tabular}

